Check for updates

Cite this: RSC Adv., 2020, 10, 2389

Received 14th October 2019

Accepted 17th December 2019

DOI: $10.1039 / \mathrm{c} 9 \mathrm{ra0} 0392 \mathrm{~h}$

rsc.li/rsc-advances

\section{A dielectric and spectrophotometric study of the tautomerization of 2-hydroxypyridine and 2- mercaptopyridine in water $\dagger$}

\begin{abstract}
Biswadeep Bomzon, Yashita Khunger and Ranga Subramanian (D) *
The basic ionization $\left(p k_{1}\right)$ and acidic ionization $\left(p k_{2}\right)$ constants and equilibrium constant $\left(K_{T}\right)$ of $2 \mathrm{HPy}$ and 2MPy were determined. The $\mathrm{p} k_{1}(\mathrm{~s})$ of their $\mathrm{N}$ - and $\mathrm{X}$-methyl derivatives $(\mathrm{X}=\mathrm{O}, \mathrm{S})$ were also determined. The equilibrium constant of $2 \mathrm{MPy}$ is approximately 60 times greater than its oxygen analog, $2 \mathrm{HPy}$. The micro-ionization constants of the functional groups, $-\mathrm{NH}\left(\mathrm{p} k_{\mathrm{A}}\right.$ and $\left.\mathrm{p} k_{\mathrm{C}}\right)$ and $-\mathrm{XH}\left(\mathrm{p} k_{\mathrm{B}}\right.$ and $\left.\mathrm{p} k_{\mathrm{D}}\right)$, were determined to provide further insights into the ionization equilibria of these $\mathrm{N}$-heteroaromatic $\mathrm{XH}$ compounds (2HPy and 2MPy). The relaxation time of water $(\tau)$ in aqueous solutions of $2 \mathrm{HPy}$ and $2 \mathrm{MPy}$ are collectively used with the $K_{\mathrm{T}}$ values to determine the forward $\left(k_{\mathrm{f}}\right)$ and backward $\left(k_{\mathrm{b}}\right)$ rate constants of tautomerization. Subsequently, the $k_{\mathrm{f}}$ and $k_{\mathrm{b}}$ are used to provide the rationale for the $K_{\mathrm{T}}$ and $\tau$ values.
\end{abstract}

\section{Introduction}

Tautomerism is the dynamic equilibrium between molecules with the same atomic composition and the proton transfer between two electronegative atoms within the same molecule. The interconversion is associated with a small potential energy barrier. ${ }^{1,2}$ Research on tautomerism covers scientific fields ranging from chemistry, biochemistry to chemical physics. These studies are of fundamental importance in the interpretation of reaction mechanisms involving tautomers, such as to stabilize covalent organic framework; ${ }^{3}$ in designing computeraided drug and their biological effects, ${ }^{4,5}$ and as molecular switches. ${ }^{6,7}$

The keto-enol tautomerism process in various systems (especially 2-pyridone, 2Py) has received attention as one of the simplest prototype systems to study proton shuttling, hydrogen bonding, and tautomerism mechanisms. Fig. 1 illustrates the rapid and facile tautomeric transformations. Indeed, $2 \mathrm{Py}$ is a heteroaromatic system to describe hydrogen-bonded DNA base pairs; ${ }^{8}$ catalytic design element; ${ }^{9}$ with potential for selfassembly platform of bidentate ligands ${ }^{10}$ and blocks in synthesis. ${ }^{11}$ Some of the nucleic acid bases exhibit the keto-enol tautomerism, in which proton transfer takes place between $\mathrm{N}$ and $\mathrm{O}$ sites of the molecules and may be one of the possible routes for the DNA and RNA mutations. ${ }^{12-14}$ From the theoretical and experimental studies that have been reported, ${ }^{15-23}$ it can be gleaned that in pyridine and pyrimidine substituted at 2- or 4-

Department of Chemistry, Indian Institute of Technology Patna, 801106 India. E-mail: ranga@iitp.ac.in

$\dagger$ Electronic supplementary information (ESI) available. See DOI: 10.1039/c9ra08392h positions by tautomeric groups $\mathrm{XH}(\mathrm{X}=\mathrm{O}$ or $\mathrm{S})$ exist in lactam or thione forms rather than in lactim or thiol forms.

The rate constants $\left(k_{\mathrm{f}}\right.$ and $k_{\mathrm{b}}$ ) of tautomerization are critical parameters to determine the time required to attain the state of equilibrium between the tautomers. The rate constants also provide valuable insights on the stabilities of the tautomeric forms and their respective concentrations in the system. The tautomeric concentrations in the system are crucial since it has been found that several models of spontaneous mutations in DNA involve the role of minor tautomeric forms. ${ }^{14,24}$ It has also been reported that the minor tautomeric forms are included in the stabilization of anomalous DNA structures..$^{25-30}$ The rate of mutation tends to increase with the increase in the formation of minor tautomers, thus any situations that would cause the high mutation rates can be avoided for the genetic material. ${ }^{31}$ Analysis of rate constants of tautomerization can also be constructive in the development of lethal antiviral mutagenesis for the treatment of virus-like HIV. ${ }^{32}$

The tautomers present in the solution containing more than one functional group would gain or lose protons, depending on the $\mathrm{pH}$ of the medium. This ionization of functional groups occurs at the molecular level, cannot be determined empirically and is called micro-ionization constants. On the contrary, the macro-ionization (ionization) constants can be measured using

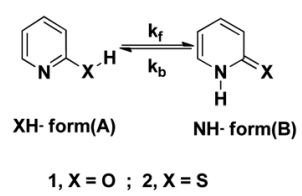

Fig. 1 Tautomerization of $\mathrm{N}$-heteroaromatic $\mathrm{XH}$ compounds. 
a potentiometric method, a spectrophotometric method, or by NMR. The ionization constants correspond to the simultaneous ionization of functional groups and are hybrid values of microionization constants. ${ }^{33}$ There is a negligible influence of acidbase equilibria on the stabilization of the physiological structures of DNA since the nucleic acid bases are neutral under normal physiological conditions. Nevertheless, the evaluation of ionization and microionization constants cannot be taken for granted, for it has been suggested that the ionization may be relevant in deciding the mutagenic properties of the analogs of nucleic acid bases. ${ }^{34}$ It is also reported that the DNA polymerase can merge the ionized base pairs into DNA. ${ }^{35}$

Dielectric Relaxation Spectroscopy (DRS) is a tool to study the structure and dynamics of the complex liquid fluids whose properties are dominated by hydrogen bonding and is adequate for an investigation of hydrogen bond rearrangement dynamics. DRS has been widely applied for investigating pure solvents, ${ }^{36-42}$ solvent-solvent mixtures, ${ }^{43}$ super-cooled, and glass-forming liquids, ${ }^{44-48}$ water-organic compound mixtures, ${ }^{49-60}$ and electrolyte solutions. In-depth knowledge in hydrogen bond is required to understand the nature of molecular interactions taking place in biological activities; enzyme catalysis, drug synthesis and chemical and electrical properties of the material. ${ }^{61-68}$

2-Hydroxypyridine (2HPy) $(1 \mathrm{~A} \rightleftharpoons 1 \mathrm{~B})$ and 2-mercaptopyridine ( $2 \mathrm{MPy})(2 \mathrm{~A} \rightleftharpoons 2 \mathrm{~B})$ in aqueous solutions have been studied, experimentally $^{69-73}$ and theoretically. ${ }^{74-81}$ To the best of our knowledge, this is the first study that determines the rate constants, $k_{\mathrm{f}}$, and $k_{\mathrm{b}}$ (of tautomerization) in aqueous medium, as depicted in Fig. 1.

The spectrophotometric approach is employed to determine the acidic and basic ionization constants, $k_{1}$ and $k_{2}$, of $2 \mathrm{HPy}$ and 2MPy along with the basic ionization constants of their respective $N$-methyl and $X$-methyl derivatives, $k_{1 \text { (NMe) }}$ and $k_{1 \text { (хмe). }}$. The equilibrium constant $\left(K_{\mathrm{T}}\right)$ of aqueous solutions of 2HPy and 2MPy was determined using ionization constant. The equilibrium constants, in turn, were used to calculate the micro-ionization constants, $k_{\mathrm{A}}, k_{\mathrm{B}}, k_{\mathrm{C}}$, and $k_{\mathrm{D}}$, of the $\mathrm{NH}$ and $\mathrm{XH}$ functional groups present in both 2HPy and 2MPy. The outcomes of the spectrophotometric approach alone were inadequate to provide the values of the $k_{\mathrm{f}}$ and $k_{\mathrm{b}}$ directly. DRS is used to investigate the tautomerization of aqueous solutions of $2 \mathrm{HPy}$ and $2 \mathrm{MPy}$. DRS provides the relaxation time in an aqueous solution of $2 \mathrm{HPy}\left(\tau_{2 \mathrm{HPy}}\right)$ and $2 \mathrm{MPy}\left(\tau_{2 \mathrm{MPy}}\right)$, which were used to find the $k_{\mathrm{f}}$ and $k_{\mathrm{b}}$ of tautomerization. Thus, DRS, together with spectrophotometry, were combined to determine the rate constants of tautomerization, $k_{\mathrm{f}}$, and $k_{\mathrm{b}}$, for the first time.

\section{Results and discussions}

For 2HPy, and 2MPy, aqueous solutions are prepared in the concentration range of $0.168 \times 10^{-5}$ to $11.777 \times 10^{-5} \mathrm{M}$, in such a way that the absorbance values of these solutions remain lower than or closer to unity (see Fig. 2).

Fig. 2 indicates the presence of two $\lambda_{\max }$, which corresponds to the two tautomers, $\mathrm{NH}$ - and $\mathrm{XH}$ forms. It can also be inferred
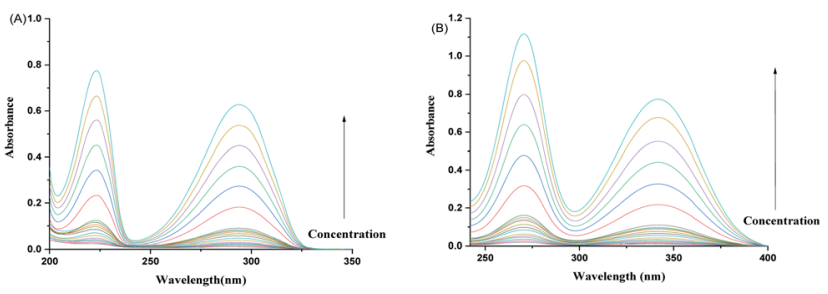

Fig. 2 Absorption spectra of aqueous solutions of (A) 2HPy and (B) $2 \mathrm{MPy}$ in the concentration range of $(0.168-11.776) \times 10^{-5} \mathrm{M}$.

from the Fig. 2, that the dimers (both homo- and hetero-) are absent in the system. As a consequence, it can be drawn that the tautomers of both 2HPy and 2MPy prefer to form hydrogen bonds (H-bonds) with water molecules rather than to make $\mathrm{H}$ bonds between them. Indeed the self-association of tautomers in water is thermodynamically unfavorable. ${ }^{\mathbf{8}}$ Therefore, the tautomerization of $\mathrm{N}$-heteroaromatic $\mathrm{XH}$ compounds can be presented as in Fig. 1, without any elaborations. Comparing Fig. $2 \mathrm{a}$ and $\mathrm{b}, \lambda_{\max }$ corresponding to $\mathrm{XH}$ and $\mathrm{NH}$ forms, shifts towards longer wavelength (lower energy difference) from $2 \mathrm{HPy}$ $(223 \mathrm{~nm} ; 294 \mathrm{~nm})$ to $2 \mathrm{MPy}(271 \mathrm{~nm} ; 342 \mathrm{~nm})$. This shift in the $\lambda_{\max }$ might be because the polar solvent $\left(\mathrm{H}_{2} \mathrm{O}\right)$ stabilizes the electronic ground states of $2 \mathrm{HPy}$, thereby increasing the energy difference between the concerned electronic states of 2HPy in comparison to the $2 \mathrm{MPy}$ molecules. ${ }^{89}$ From Fig. 3, it's clear that the systems of our interest follow the Beer-Lambert's law. The experiment result (see, Fig. 2(A) and 3(A)) also reveals that the $\mathrm{OH}$-form of $2 \mathrm{HPy}$ is detected only from $0.252 \times 10^{-5} \mathrm{M}$. It's probably the $\mathrm{OH}$-form is undetectable at lower concentrations (below $0.252 \times 10^{-5} \mathrm{M}$ ) in comparison to the $\mathrm{NH}$-form in aqueous solutions. In the case of $2 \mathrm{MPy}$, both peaks are present at lower concentrations. This result is consistent with the molar absorption coefficient values of $2 \mathrm{MPy} ; \varepsilon_{2 \mathrm{MPy}}$ is higher than the molar absorption coefficient of $2 \mathrm{HPy}, \varepsilon_{2 \mathrm{HPy}}$ (Fig. 2). ${ }^{21,90}$

Spectrophotometric measurements allow us to assess the acidic $\left(k_{2}\right)$ and basic $\left(k_{1}\right)$ ionization constants by addition of protons $\left(\mathrm{H}^{+}\right)$and hydroxyl ions $\left(\mathrm{OH}^{-}\right)$to form the cationic $\left(\mathrm{Q}^{+}\right)$ and anionic forms $\left(\mathrm{Q}^{-}\right)$respectively, of $\mathrm{N}$-heteroaromatic $\mathrm{XH}$ compounds respectively (see Fig. 4).

Applying eqn (7), the $\mathrm{p} k_{2}(\mathrm{~s})$, of $2 \mathrm{HPy}$, and $2 \mathrm{MPY}$ were calculated (see Table S2 and S3†), then using eqn (9), p $k_{1}$ of 2 HPy was obtained. Likewise, the basic ionization constants of 2methoxypyridine ( $\left.\mathrm{p} k_{\mathrm{OMe}}\right)$ and $N$-methyl-pyridone $\left(\mathrm{p} k_{1(\mathrm{NMe})}\right)$ were also obtained using eqn (9), and the basic ionization constant of
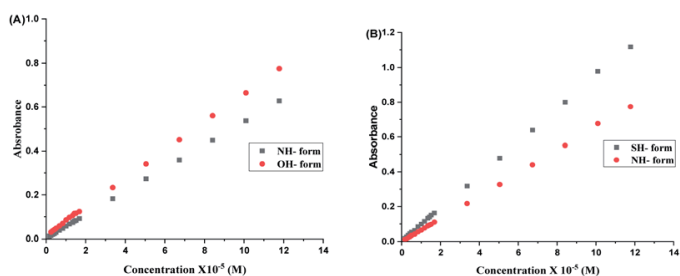

Fig. 3 Concentration $\left(\times 10^{-5} \mathrm{M}\right.$ ) versus absorbance plots of aqueous solutions of (A) 2HPy and (B) 2MPy. 


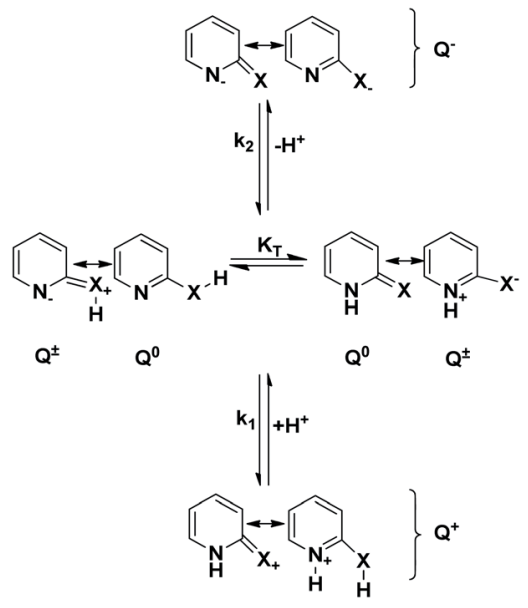

Fig. 4 Ionization equilibria of $\mathrm{N}$-heteroaromatic $\mathrm{XH}$ compounds. $\mathrm{Q}^{0}$ represent the neutral forms, and $Q^{ \pm}$represent the zwitterionic form.

2-methylthiopyridine $\left(\mathrm{p} k_{\mathrm{SMe}}\right)$ was evaluated using eqn (10) as given in Tables $\mathrm{S} 1, \mathrm{~S} 4, \mathrm{~S} 5$, and $\mathrm{S} 6 \dagger$ respectively. Table 1 provides the ionization constants, $\mathrm{p} k_{1}, \mathrm{p} k_{2}, \mathrm{p} k_{1(\mathrm{NMe})}$, and $\mathrm{p} k_{1(\mathrm{xMe})}$, and the calculated values of $K_{\mathrm{T}}(\mathrm{s})$. The equilibrium constant $\left(K_{\mathrm{T}}\right)$ of the tautomerism $(\mathrm{A} \rightleftharpoons \mathrm{B})$, of $\mathrm{N}$-heteroaromatic $\mathrm{XH}$-compounds in aqueous solutions, are evaluated from the ionization constants of 2HPy and 2MPy and their $X$ - and $N$-methyl derivatives using eqn (4) or (5). ${ }^{91,92}$

Table 1 shows that $\mathrm{p} k_{1}, \mathrm{p} k_{1(\mathrm{xMe})}, \mathrm{p} k_{1(\mathrm{NMe})}$ of $2 \mathrm{HPy}$ are in agreement with the literature values while $\mathrm{p} k_{2}$ of $2 \mathrm{HPy}$ and $\mathrm{p} k_{2}$, $\mathrm{p} k_{1(\mathrm{XMe})}$ of $2 \mathrm{MPy}$ are close to the literature values. ${ }^{19,83,84,92} K_{\mathrm{T}}$ and $\Delta G$ values of $2 \mathrm{HPy}$ and $2 \mathrm{MPy}$ are comparable to the literature values. ${ }^{19,83,93}$ The $K_{\mathrm{T}}$ and $\Delta G$ values of the $2 \mathrm{HPy}$ and $2 \mathrm{MPy}$ show that the $\mathrm{NH}-$ tautomers are predominant over the $\mathrm{XH}-$ tautomers. ${ }^{94-96}$ As a consequence, we can infer that the forward rate constant, $k_{\mathrm{f}}$, is higher than the backward rate constant, $k_{\mathrm{b}}$, of $\mathrm{N}-$ heteroaromatic XH compounds in water. Further, the $K_{\mathrm{T}}$ and $\Delta G$ of 2MPy are approximately 60 and 1.6 times greater than that of $2 \mathrm{HPy}$. This difference is probably due to the differences in the values of their rate constants, $k_{\mathrm{f}}$, and $k_{\mathrm{b}}$. The $\mathrm{p} k_{1}$ and $\mathrm{p} k_{2}$, determined experimentally, are composite and are related to the micro-ionization constants of the individual functional groups

Table 1 The ionization constants $\left(k_{1}\right.$ and $\left.k_{2}\right)$, of 2HPy and 2MPy, their $X$ - and $N$-methyl derivatives $\left(k_{1(\mathrm{XMe})}\right.$ and $\left.k_{1(\mathrm{NMe})}\right)$ and the equilibrium constants $\left(K_{\mathrm{T}}=[\mathrm{B}] /[\mathrm{A}]\right)$ in the water at room temperature

\begin{tabular}{lcl}
\hline$k_{1}, k_{2}, K_{\mathrm{T}}, \Delta G$ & 2-Hydroxypyridine & 2-Mercaptopyridine \\
\hline $\mathrm{p} k_{1}$ & $0.76 \pm 0.01(0.75)$ & $-1.38^{a}(-)$ \\
$\mathrm{p} k_{2}$ & $12.14 \pm 0.02(11.62)$ & $10.10 \pm 0.01(9.81)$ \\
$\mathrm{p} k_{1(\mathrm{xMe})}$ & $3.25 \pm 0.01(3.28)$ & $3.37 \pm 0.01(3.59)$ \\
$\mathrm{p} k_{1(\mathrm{NMe})}$ & $0.31 \pm 0.01(0.32)$ & - \\
$K_{\mathrm{T}}$ & $912 \pm 29(910)$ & $56230 \pm 1000(70000)$ \\
$\log K_{\mathrm{T}}$ & $2.96 \pm 0.01(2.96)$ & $4.75 \pm 0.01(4.82)$ \\
$\Delta G\left(\mathrm{~kJ} \mathrm{~mol}^{-1}\right)$ & $-16.88 \pm 0.06(-16.90)$ & $-27.09 \pm 0.06(-27.50)$
\end{tabular}

${ }^{a}$ From ref. 17. The literature values are listed in the parenthesis.

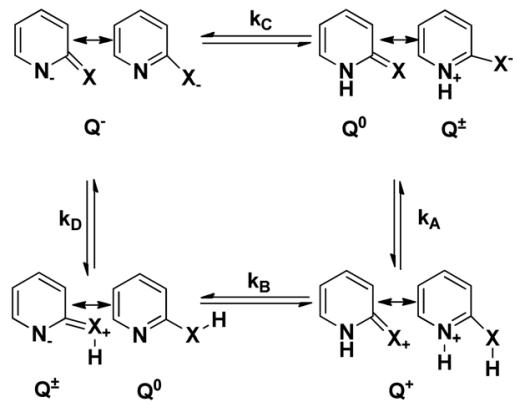

Fig. 5 Micro-ionization equilibria of $\mathrm{N}$-heteroaromatic $\mathrm{XH}$ compounds. $Q^{-}$represents the anionic forms, and $Q^{+}$represents the cationic forms of the tautomers.

- $\mathrm{NH}\left(k_{\mathrm{A}}\right.$ and $\left.k_{\mathrm{C}}\right)$ and $-\mathrm{XH}\left(k_{\mathrm{B}}\right.$ and $\left.k_{\mathrm{D}}\right)$ of the $\mathrm{N}$ - heteroaromatic compounds by the following expressions. ${ }^{33,83}$

$$
\begin{gathered}
k_{1}=k_{\mathrm{A}}+k_{\mathrm{B}} \\
1 / k_{2}=1 / k_{\mathrm{C}}+1 / k_{\mathrm{D}} \\
k_{1} k_{2}=k_{\mathrm{A}} k_{\mathrm{C}}=k_{\mathrm{B}} k_{\mathrm{D}}
\end{gathered}
$$

The micro-ionization constants are not independent of each other since the ionization of their respective functional groups can follow either of the two paths depicted in Fig. 5 .

In the case of $2 \mathrm{HPy}$, the basic micro-ionization constants of the $\mathrm{NH}$ and $\mathrm{XH}$ tautomers $\left(k_{\mathrm{A}}\right.$ and $\left.k_{\mathrm{B}}\right)$ are assumed to be equal to the basic ionization constants of $N$-methyl $\left(k_{1(\mathrm{NMe})}\right)$ and $X$ methyl $\left(k_{1(\mathrm{xMe})}\right)$ derivatives. ${ }^{83}$ Eqn (4) gives the relationship between $K_{\mathrm{T}}$ and the microionization constants $\left(k_{\mathrm{C}}\right.$ and $\left.k_{\mathrm{D}}\right)$.

$K_{\mathrm{T}}=k_{\mathrm{f}} / k_{\mathrm{b}}=[\mathrm{NH}$ form $] /[\mathrm{XH}$ form $]=k_{\mathrm{A}} / k_{\mathrm{B}}=k_{\mathrm{D}} / k_{\mathrm{C}}=k_{1(\mathrm{NMe})} /$

$k_{1(\mathrm{XMe})}$

On the other hand, for $2 \mathrm{MPy}$, the $K_{\mathrm{T}}$ was determined by employing the basic ionization constants of $2 \mathrm{MPy}\left(k_{1}\right)$ and its $X$ methyl derivative $\left(k_{1(\mathrm{XMe})}\right)$ by the following equation. ${ }^{83}$

$$
K_{\mathrm{T}}=\left(k_{1} / k_{1(\mathrm{XMe})}\right)-1
$$

Table 2 Micro-ionization constants of $\mathrm{XH}\left(k_{\mathrm{B}}\right.$ and $\left.k_{\mathrm{D}}\right)$ and the $\mathrm{NH}$ tautomers $\left(k_{A}\right.$ and $\left.k_{C}\right)$ of the 2HPy and 2MPy in the water at room temperature ${ }^{a}$

\begin{tabular}{lcr}
$\begin{array}{l}\text { Micro-ionization } \\
\text { constants }\end{array}$ & 2-Hydroxypyridine & 2-Mercaptopyridine \\
\hline $\mathrm{p} k_{\mathrm{A}}$ & $0.76 \pm 0.02(0.75)$ & $-1.38 \pm 0.01$ \\
$\mathrm{p} k_{\mathrm{B}}$ & $3.72 \pm 0.01(3.71)$ & $3.37 \pm 0.01$ \\
$\mathrm{p} k_{\mathrm{C}}$ & $12.14 \pm 0.02(11.62)$ & $10.10 \pm 0.01$ \\
$\mathrm{p} k_{\mathrm{D}}$ & $9.18 \pm 0.03(8.66)$ & $5.35 \pm 0.01$
\end{tabular}

${ }^{a}$ The values of $\mathrm{p} k_{\mathrm{A}}$ and $\mathrm{p} k_{\mathrm{B}}$ for $2 \mathrm{HPy}$ are identical to the literature values, and $\mathrm{p} k_{\mathrm{C}}$ and $\mathrm{p} k_{\mathrm{D}}$ are comparable. ${ }^{82} T \mathrm{The} \mathrm{p} k_{\mathrm{A}}, \mathrm{p} k_{\mathrm{B}}, \mathrm{p} k_{\mathrm{C}}$, and $\mathrm{p} k_{\mathrm{D}}$ of $2 \mathrm{MPy}$ are reported for the first time in this work. 

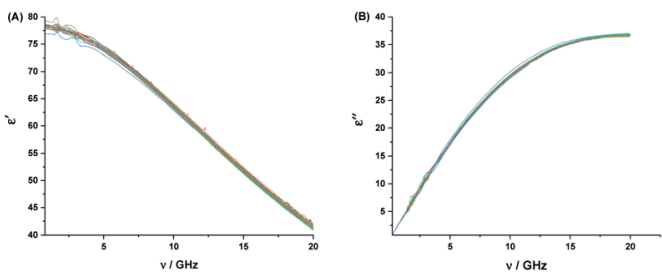

Fig. 6 Real $\left(\varepsilon^{\prime}\right)(A)$, and imaginary $\left(\varepsilon^{\prime \prime}\right),(B)$, parts of the complex dielectric function for aqueous solutions of $2 \mathrm{HPy}$ at the concentration range of $0.168-1000 \times 10^{-5} \mathrm{M}$, at room temperature.

The micro-ionization constant of the tautomers of both $2 \mathrm{HPy}$ and 2MPy are calculated from the values given in Table 1, using eqn (1)-(4) and is shown in Table 2.

The aqueous solutions of $2 \mathrm{HPy}$ and $2 \mathrm{MPy}$ in the concentration range of $(0.168-1000) \times 10^{-5} \mathrm{M}$ were used to record the DRS at room temperature. The real $\left(\varepsilon^{\prime}\right)$ and imaginary $\left(\varepsilon^{\prime \prime}\right)$ parts of the dielectric spectra of these solutions were plotted against the frequency $(\nu)$. Fig. (6) and (7) show the plots, respectively.

From Fig. (6) and (7), it is observed that both the real and imaginary parts of the dielectric spectra of the aqueous solutions of both $2 \mathrm{HPy}$ and $2 \mathrm{MPy}$ resemble the pure water. We had varied the concentrations from $(0.168$ to 1000.00$) \times 10^{-5} \mathrm{M}$; their spectra are inseparable from pure water as well as from each other. It is inferred that the water domain changes very little with the addition of both $2 \mathrm{HPy}$ and $2 \mathrm{MPy}$. Thus, the oneterm Debye function can be applied to the dielectric spectra conveniently during fitting. The error to the parameters, $\varepsilon_{\alpha}, \Delta \varepsilon$, $\varepsilon_{\mathrm{s}}$, and $\tau$, were determined using error analysis ${ }^{97}$ and are given in parenthesis in Tables S15 and S16. $\uparrow$ Tables S15 and $\mathrm{S} 16 \dagger$ reveal that the $\varepsilon_{\alpha}, \Delta \varepsilon$, and $\varepsilon_{\mathrm{s}}$ are close to values of pure water. The $\tau_{\mathrm{w}}$ values decrease only slightly from that of pure water. The $\tau$ remains virtually unchanged with the concentration variations for 2HPy solutions and 2MPy solutions in water. The $\tau$ values indicate that the $\tau$ of $2 \mathrm{HPy}$ and $2 \mathrm{MPy}$ is independent of the concentrations of the solutes, as shown in Fig. 8. As a consequence, the $\tau$ can be expressed as the reciprocal of the sum of the $k_{\mathrm{f}}$ and $k_{\mathrm{b}}$ as shown below, ${ }^{98}$

$$
\tau=1 /\left(k_{\mathrm{f}}+k_{\mathrm{b}}\right)
$$

Fig. 8 shows a linear fit of $\tau$ and concentration. From the fit, we get intercepts for 2HPy of 8.02(3) ps and 2MPy of 8.19(2) ps with slope nearly zero. Indeed, this implies DRS provides
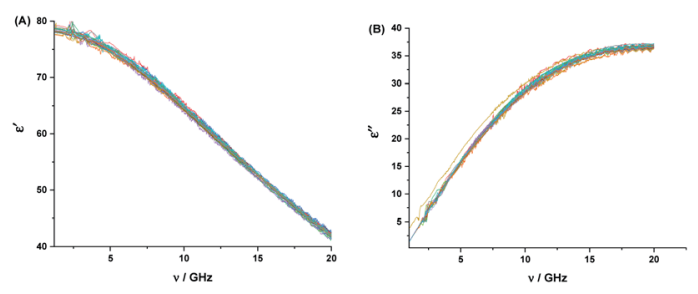

Fig. 7 Real $\left(\varepsilon^{\prime}\right)(A)$, and imaginary $\left(\varepsilon^{\prime \prime}\right),(B)$, parts of the complex dielectric function for aqueous solutions of $2 \mathrm{MPy}$ at the concentration range of $0.168 \times 10^{-5}$ to $1000 \times 10^{-5} \mathrm{M}$, at room temperature.
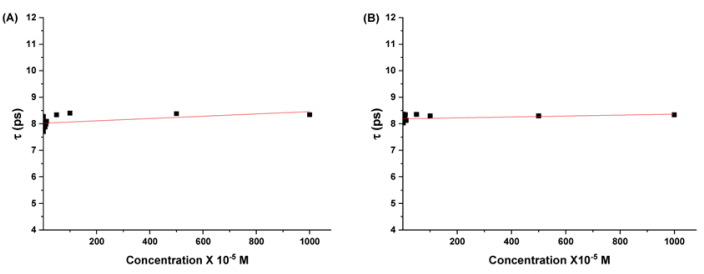

Fig. 8 Relaxation times of water, $\tau$ against the concentration of aqueous solutions of (A) 2HPY, and (B) 2MPy.

Table 3 The relaxation times $(\tau)$ of water and rate constants, $k_{\mathrm{f}}$ and $k_{\mathrm{b}}$, of tautomerization $(\mathrm{A} \rightleftharpoons \mathrm{B}$ ) in aqueous solutions of $2 \mathrm{HPy}$ and $2 \mathrm{MPy}$

\begin{tabular}{llll}
\hline Compounds & $\tau(\mathrm{ps})$ & $k_{\mathrm{f}}\left(\mathrm{in} \mathrm{s}^{-1}\right)$ & $k_{\mathrm{b}}\left(\right.$ in s $\left.^{-1}\right)$ \\
\hline $2 \mathrm{HPy}$ & $8.02(3)$ & $(1.24 \pm 0.05) \times 10^{11}$ & $(1.36 \pm 0.04) \times 10^{8}$ \\
$2 \mathrm{MPy}$ & $8.19(2)$ & $(1.22 \pm 0.04) \times 10^{11}$ & $(2.18 \pm 0.04) \times 10^{6}$
\end{tabular}

a crucial relation between the $\tau$, and $k_{\mathrm{f}}$ and $k_{\mathrm{b}}$. By combining eqn (11) and (13), the values of rate constants, $k_{\mathrm{f}}$, and $k_{\mathrm{b}}$ are evaluated (see Table 3 ).

From Table (3), it is seen that the $k_{\mathrm{f}}$ values of tautomerization of both $2 \mathrm{HPy}(1 \mathrm{~A} \rightleftharpoons 1 \mathrm{~B})$ and $2 \mathrm{MPy}(2 \mathrm{~A} \rightleftharpoons 2 \mathrm{~B})$ are higher than the $k_{\mathrm{b}}$ values since the $\mathrm{NH}$-forms are more stable than their $\mathrm{XH}$ forms, due to the fact that the free $\mathrm{X}$-atoms are readily available for stronger hydrogen bonding with water molecules. ${ }^{99}$ The similarity of the $k_{\mathrm{f}}$ values of both the N-heteroaromatic $\mathrm{XH}$ compounds can be explained because their stability of $\mathrm{NH}^{-}$ forms in water is almost identical. The $k_{\mathrm{b}}$ values of $2 \mathrm{HPy}$ are higher than that of $2 \mathrm{MPy}$ by a magnitude of about 60 . The difference in the $k_{\mathrm{b}}$ values can be explained on the basis that the $\mathrm{XH}$ forms of $2 \mathrm{HPy}$ are more stable than the same form of 2MPy in water. Since the $\mathrm{OH}$ group forms stronger hydrogen bonds with water molecules, which increases the stability of $\mathrm{XH}$-form of $2 \mathrm{HPy}$ in water and, the SH group, on the other hand, cannot form strong hydrogen bonds with water molecules. So, the $\mathrm{XH}$ form of 2MPy is less stable.

\section{Conclusions}

The aqueous solutions of both 2HPy and 2MPy obey the Debye equation. The NH-forms of both $2 \mathrm{HPy}$ and $2 \mathrm{MPy}$ are predominant over their $\mathrm{XH}$-forms. The $\mathrm{NH}$-tautomer forms stronger hydrogen bonds with water molecules than their XH-tautomers. The equilibrium constant $\left(K_{\mathrm{T}}\right)$ of $2 \mathrm{MPy}(2 \mathrm{~A} \rightleftharpoons 2 \mathrm{~B})$ is approximately 60 times greater than the equilibrium constant $\left(K_{\mathrm{T}}\right)$ of $2 \mathrm{HPy}(1 \mathrm{~A} \rightleftharpoons 1 \mathrm{~B})$. The backward rate constant $\left(k_{\mathrm{b}}\right)$ of $2 \mathrm{HPy}$ is higher than that of $2 \mathrm{MPy}$ by the value of 60 , while the forward rate constant $\left(k_{\mathrm{f}}\right)$ is identical. The $\mathrm{NH}$-forms have equivalent stabilities, while the $\mathrm{XH}$-form of $2 \mathrm{HPy}$ is more stable than the same form of its sulfur analog, 2MPy. The XH-form of $2 \mathrm{HPy}$ forms stronger hydrogen bonds with water molecules through $-\mathrm{OH}$ groups. The $-\mathrm{SH}$ groups do not form stronger hydrogen bonds with water molecules; hence, $\mathrm{XH}$-form of $2 \mathrm{MPy}$ is less stable. 


\section{Experimental section}

Commercially purchased 2HPy (Alfa Aesar, 98+ \%), 2MPy (Alfa Aesar, 98\%), 2-(methylthio) pyridine (Sigma Aldrich, with $\geq$ 95\%), $N$-methyl-2-pyridone (Sigma Aldrich, with $\geq 99 \%$ ) and 2methoxypyridine (Sigma Aldrich, with 98\%) was used. The solutions, in molarity (M), were prepared using triple distilled water. The $\mathrm{pH}(\mathrm{s})$ of the prepared solutions and buffers were measured using a digital pH meter, PC 2700-Oakton, and a combined glass $\mathrm{pH}$ electrode. Commercial standardized buffer solutions of $\mathrm{pH}=4,7$, and 10 were used for calibration of the combined electrode. Buffers $(0.01 \mathrm{M})$ of low ultraviolet absorption (glycine, borate, acetate, and formate) were used. UV-Visible spectrophotometer, Shimadzu (UV- 2550), was used in spectrophotometric measurements (200-400 nm). The sample cuvettes used are of quartz (Hellma Analytics) with $1 \mathrm{~cm}$ path length.

The aqueous concentrations in the range of $10^{-4}$ to $10^{-5} \mathrm{M}$ were used for accurate determination of the ionization constants. ${ }^{82}$ The literature values of ionization constants for different compounds, determined from the potentiometric techniques ${ }^{19,83,84}$ were chosen as the estimated values of ionization constants. Appropriate buffers were prepared for the determination of absorbances of the neutral forms. Suitable concentrations of the base $(\mathrm{NaOH})$ and acids $\left(\mathrm{HCl}, \mathrm{H}_{2} \mathrm{SO}_{4}\right)$ were also used in preparing the solutions for the determination of absorbances of ionic forms of the compounds. The different solutions the compounds were probed in the range of 200$400 \mathrm{~nm}$ against their suitable blanks with an identical $\mathrm{pH}$. The analytical wavelengths were chosen based on the highest difference between the absorbances of the neutral and ionic forms. The ionization constants $\left(\mathrm{p} k_{1}, \mathrm{p} k_{2}, \mathrm{p} k_{1(\mathrm{NMe})}, \mathrm{p} k_{1(\mathrm{XMe})}\right)$ were determined by employing the appropriate eqn (7)-(10).

For acidic ionization constants, $\mathrm{p} k_{1}$,

$$
\begin{aligned}
& \text { when } A_{\mathrm{I}}>A_{\mathrm{M}}, \mathrm{p} k_{1}=\mathrm{pH}+\log \left(A_{\mathrm{I}}-A\right) /\left(A-A_{\mathrm{M}}\right) \\
& \text { when } A_{\mathrm{M}}>A_{\mathrm{I}}, \mathrm{p} k_{1}=\mathrm{pH}+\log \left(A-A_{\mathrm{I}}\right) /\left(A_{\mathrm{M}}-A\right)
\end{aligned}
$$

For basic ionization constants, $\mathrm{p} k_{2}$,

$$
\begin{aligned}
& \text { when } A_{\mathrm{I}}>A_{\mathrm{M}}, \mathrm{p} k_{2}=\mathrm{pH}+\log \left(A-A_{\mathrm{M}}\right) /\left(A_{\mathrm{I}}-A\right) \\
& \text { when } A_{\mathrm{M}}>A_{\mathrm{I}}, \mathrm{p} k_{2}=\mathrm{pH}+\log \left(A_{\mathrm{M}}-A\right) /\left(A-A_{\mathrm{I}}\right)
\end{aligned}
$$

where $A_{\mathrm{I}}$ is the absorbance of the ionic forms, $A_{\mathrm{M}}$ is the absorbance of a neutral form, and $\mathrm{A}$ is the absorbance of species in the buffer solutions.

Agilent E5071C Vector Network Analyzer (VNA) with an Agilent E85070E dielectric probe kit was calibrated against the calibration standards, air, short circuit, and water. The Agilent $85070 \mathrm{E}$ dielectric software was used to measure the complex permittivity spectra of the pure triple distilled water and various aqueous solutions of $2 \mathrm{HPy}$ and $2 \mathrm{MPy}$, in the frequency range of $88 \mathrm{MHz}$ to $20 \mathrm{GHz}$ at room temperature.

The real and imaginary dielectric spectra, obtained from the VNA were fitted simultaneously using a non-linear least square method based on the Levenberg-Marquardt algorithm ${ }^{85}$ in Origin 2018b according to the Debye equation, as shown below,

$$
\varepsilon^{*}(\nu)=\varepsilon^{\prime}-\mathrm{i} \varepsilon^{\prime \prime}=\varepsilon_{\alpha}+\Delta \varepsilon /(1+2 \pi \mathrm{i} \nu \tau)
$$

where, $\mathrm{i}=\sqrt{ }-1, \nu=$ frequency (in $\mathrm{GHz}$ ), $\varepsilon_{\alpha}=$ high frequency dielectric permittivity, $\Delta \varepsilon=\varepsilon_{\mathrm{s}}-\varepsilon_{\alpha}=$ relaxation amplitude, $\varepsilon_{\mathrm{s}}=$ static permittivity, $\tau=$ relaxation time of water (in ps). It is familiar that pure water conforms to eqn (11) (ref. 41 and 86), but the aqueous solutions of 2HPy and 2MPy may not necessarily agree with the Debye function. Thus, to verify our concern, $\varepsilon^{\prime}(\omega)$ against $\varepsilon^{\prime \prime}(\omega) / \omega$, and $\varepsilon^{\prime}(\omega)$ against $\omega \varepsilon^{\prime \prime}(\omega)$ were plotted according to the eqn (12) and (13), which are rearranged versions of Debye equation. ${ }^{87}$

$$
\begin{aligned}
& \varepsilon^{\prime}(\omega)=\varepsilon_{\alpha}+\frac{1}{\tau} \frac{\varepsilon^{\prime \prime}(\omega)}{\omega} \\
& \varepsilon^{\prime}(\omega)=\varepsilon_{s}-\tau \omega \varepsilon^{\prime \prime}(\omega)
\end{aligned}
$$

where, $\omega=2 \pi \nu=$ angular frequency.

Straight lines with slope $(=1 / \tau)$ and intercept $\left(=\varepsilon_{\alpha}\right)$, from eqn (12) and slope $(=-\tau)$ and intercept $\left(=\varepsilon_{\mathrm{s}}\right)$, from eqn (13) were obtained which are similar to that obtained from fitting the dielectric spectra using non-linear least squares procedures based on the Levenberg-Marquardt algorithm, as seen in the Tables S7-S14 (ESI $\dagger$ ).

\section{Conflicts of interest}

There are no conflicts to declare.

\section{Acknowledgements}

The authors are thankful to the Indian Institute of Technology, Patna, for providing the opportunity to perform this work and to avail research facilities in the institute and financial support. The authors are also thankful to the Department of Physics, IIT Patna for the cooperation in the usage of Vector Network Analyzer.

\section{Notes and references}

1 J. Elguero, A. R. Katritzky and O. V. Denisko, Adv. Heterocycl. Chem., 2000, 76, 1-84.

2 E. D. Raczyńska, W. Kosińska, B. Ośmiałowski and R. Gawinecki, Chem. Rev., 2005, 105, 3561-3612.

3 H. Xu, J. Gao and D. Jiang, Nat. Chem., 2015, 7, 905.

4 P. Pospisil, P. Ballmer, L. Scapozza and G. Folkers, J. Recept. Signal Transduction, 2003, 23, 361-371.

5 Y. C. Martin, J. Comput.-Aided Mol. Des., 2009, 23, 693.

6 P. Liljeroth, J. Repp and G. Meyer, Science, 2007, 317, 12031206.

7 J. L. Zhang, J. Q. Zhong, J. D. Lin, W. P. Hu, K. Wu, G. Q. Xu, A. T. S. Wee and W. Chen, Chem. Soc. Rev., 2015, 44, 29983022 . 
8 M. Piacenza and S. Grimme, Systematic quantum chemical study of DNA-base tautomers, J. Comput. Chem., 2004, 25, 83-99.

9 C. M. Moore, E. W. Dahl and N. K. Szymczak, Curr. Opin. Chem. Biol., 2015, 25, 9-17.

10 M. T. Reetz, Angew. Chem., Int. Ed., 2008, 47, 2556-2588.

11 M. Torres, S. Gil and M. Parra, New Synthetic Methods to 2Pyridone Rings, Curr. Org. Chem., 2005, 9, 1757-1779.

12 P.-O. Löwdin, Proton Tunneling in DNA and its Biological Implications, 1963, Rev. Mod. Phys., 1963, 35, 724-732.

13 B. Pullman and A. Pullman, Adv. Heterocycl. Chem., 1971, 13, 77-159.

14 M. D. Topal and J. R. Fresco, Nature, 1976, 263, 285-289.

15 A. R. Katritzky and F. W. Maine, Tetrahedron, 1964, 20, 315322.

16 J. R. Marshall and J. Walker, J. Chem. Soc., 1951, 1004-1017, DOI: $10.1039 / J R 9510001004$.

17 M. P. V. Boarland and J. F. W. McOmie, J. Chem. Soc., 1952, 3716-3722, DOI: 10.1039/JR9520003716.

18 A. Albert and G. B. Barlin, J. Chem. Soc., 1959, 2384-2396, DOI: $10.1039 / J R 9590002384$.

19 R. A. Jones and A. R. Katritzky, J. Chem. Soc., 1958, 36103613, DOI: 10.1039/JR9580003610.

20 A. Albert and G. B. Barlin, J. Chem. Soc., 1962, 3129-3141, DOI: $10.1039 / J R 9620003129$.

21 S. Stoyanov, I. Petkov, L. Antonov, T. Stoyanova, P. Karagiannidis and P. Aslanidis, Thione-thiol tautomerism and stability of 2- and 4-mercaptopyridines and 2-mercaptopyrimidines, Can. J. Chem., 1990, 68, 14821489.

22 P. Beak, F. S. Fry, J. Lee and F. Steele, J. Am. Chem. Soc., 1976, 98, 171-179.

23 J. Elguero, The Tautomerism of heterocycles, Academic Press, New York, 1976.

24 J. S. Kwiatkowski and B. Pullman, in Advances in Heterocyclic Chemistry, ed. A. R. Katritzky and A. J. Boulton, Academic Press, Int. J. Pharmaceut., 1981, vol. 8, pp. 25-33.

25 R. L. Soliva, A. Charles and F. J. Luque, J. Am. Chem. Soc., 1998, 120, 11226-11233.

26 J. Sponer, J. Leszczynski, V. Vetterl and P. Hobza, Journal of biomolecular structure \& dynamics, J. Biomol. Struct. Dyn., 1996, 13, 695-706.

27 N. Špacková, I. Berger, M. Egli and J. Šponer, J. Am. Chem. Soc., 1998, 120, 6147-6151.

28 N. U. Zhanpeisov, J. Šponer and J. Leszczynski, J. Phys. Chem. A, 1998, 102, 10374-10379.

29 R. Soliva, F. J. Luque and M. Orozco, Nucleic Acids Res., 1999, 27, 2248-2255.

30 D. Barsky and M. E. Colvin, J. Phys. Chem. A, 2000, 104, 85708576.

31 S. A. Trygubenko, T. V. Bogdan, M. Rueda, M. Orozco, F. J. Luque, J. Šponer, P. Slavíček and P. Hobza, Phys. Chem. Chem. Phys., 2002, 4, 4192-4203.

32 D. Li, B. I. Fedeles, V. Singh, C. S. Peng, K. J. Silvestre, A. K. Simi, J. H. Simpson, A. Tokmakoff and J. M. Essigmann, Proc. Natl. Acad. Sci. U. S. A., 2014, 111, E3252-E3259.
33 E. L. Mariño and A. Dominguez-Gil, Int. J. Pharm., 1981, 8, 25-33.

34 L. C. Sowers, M. F. Goodman, R. Eritja, B. Kaplan and G. V. Fazakerley, J. Mol. Biol., 1989, 205, 437-447.

35 H. Yu, R. Eritja, L. B. Bloom and M. F. Goodman, J. Mol. Biol., 1993, 268, 15935-15943.

36 J. Barthel, K. Bachhuber, R. Buchner and H. Hetzenauer, Chem. Phys. Lett., 1990, 165, 369-373.

37 J. M. G. Barthel and R. Buchner, Pure Appl. Chem., 1991, 63, 1473.

38 R. Buchner, J. Barthel and J. Stauber, Chem. Phys. Lett., 1999, 306, 57-63.

39 T. Sato and R. Buchner, J. Chem. Phys., 2003, 118, 4606-4613. 40 C. Ro/nne, L. Thrane, P.-O. Åstrand, A. Wallqvist, K. V. Mikkelsen and S. r. R. Keiding, J. Chem. Phys., 1997, 107, 5319-5331.

41 U. Kaatze, J. Chem. Eng. Data, 1989, 34, 371-374.

42 S. K. Garg and C. P. Smyth, J. Phys. Chem., 1965, 69, 12941301.

43 S. Begum, A. Vardhan, A. Chaudhary and R. Subramanian, RSC Adv., 2016, 6, 1260-1267.

44 F. Stickel, E. W. Fischer and R. Richert, J. Chem. Phys., 1996, 104, 2043-2055.

45 C. Hansen, F. Stickel, T. Berger, R. Richert and E. W. Fischer, J. Chem. Phys., 1997, 107, 1086-1093.

46 O. E. Kalinovskaya and J. K. Vij, J. Chem. Phys., 2000, 112, 3262-3266.

47 G. P. Johari, O. E. Kalinovskaya and J. K. Vij, J. Chem. Phys., 2001, 114, 4634-4642.

48 O. E. Kalinovskaya, J. K. Vij and G. P. Johari, J. Phys. Chem. A, 2001, 105, 5061-5070.

49 T. Sato, H. Niwa, A. Chiba and R. Nozaki, J. Chem. Phys., 1998, 108, 4138-4147.

50 T. Sato, A. Chiba and R. Nozaki, J. Chem. Phys., 1999, 110, 2508-2521.

51 T. Sato, A. Chiba and R. Nozaki, J. Chem. Phys., 2000, 112, 2924-2932.

52 T. Sato, A. Chiba and R. Nozaki, J. Chem. Phys., 2000, 113, 9748-9758.

53 T. Sato, A. Chiba and R. Nozaki, J. Mol. Liq., 2002, 96-97, 327-339.

54 T. Sato, A. Chiba and R. Nozaki, J. Mol. Liq., 2002, 101, 99111.

55 U. Kaatze, M. Schäfer and R. Pottel, Z. Phys. Chem., 1989, $165,103$.

56 P. Petong, R. Pottel and U. Kaatze, J. Phys. Chem. A, 2000, 104, 7420-7428.

57 S. Mashimo and N. Miura, J. Chem. Phys., 1993, 99, 98749881.

58 S. Mashimo, T. Umehara and H. Redlin, J. Chem. Phys., 1991, 95, 6257-6260.

59 J. Z. Bao, M. L. Swicord and C. C. Davis, J. Chem. Phys., 1996, 104, 4441-4450.

60 G. G. Hammes and H. O. Spivey, J. Am. Chem. Soc., 1966, 88, 1621-1625.

61 G. A. Jeffrey and W. Saenger, Hydrogen bonding in biological systems, 1992, p. 159. 
62 D. Hadzi, Theoretical treatments of hydrogen bonding, John Wiley \& Sons, Chichester, New York, Weinheim, Brisbane, Singapore, Toronto, 1997.

63 A. Karpfen and E. S. Kryachko, Chem. Phys., 2005, 310, 77-84. 64 S. Bauer, K. Moch, P. Münzner, S. Schildmann, C. Gainaru and R. Böhmer, J. Non-Cryst. Solids, 2015, 407, 384-391.

$65 \mathrm{H}$. A. Chaube, V. A. Rana, P. Hudge and A. C. Kumbharkhane, J. Mol. Liq., 2015, 211, 346-352.

66 G. Z. Jia, Q. Jie and W. Feng, J. Mol. Struct., 2015, 1100, 354358.

67 S. Sreehari Sastry, S. M. Ibrahim, M. Sailaja, T. Vishwam and H. S. Tiong, J. Mol. Liq., 2015, 212, 612-617.

68 G. Arivazhagan, R. Shanmugam and A. Elangovan, Spectrochim. Acta, Part A, 2011, 81, 172-177.

69 M. R. Nimlos, D. F. Kelley and E. R. Bernstein, J. Phys. Chem., 1989, 93, 643-651.

70 G. M. Florio, C. J. Gruenloh, R. C. Quimpo and T. S. Zwier, J. Chem. Phys., 2000, 113, 11143-11153.

71 A. Held and D. W. Pratt, J. Am. Chem. Soc., 1993, 115, 97089717.

72 Y. Matsuda, T. Ebata and N. Mikami, J. Chem. Phys., 1999, 110, 8397-8407.

73 Y. Matsuda, T. Ebata and N. Mikami, J. Chem. Phys., 2000, 113, 573-580.

74 M. J. Field and I. H. Hillier, J. Chem. Soc., Perkin Trans. 2, 1987, 617-622, DOI: 10.1039/P29870000617.

75 C. Adamo, V. Barone, S. Loison and C. Minichino, J. Chem. Soc., Perkin Trans. 2, 1993, 697-702, DOI: 10.1039/ P29930000697.

76 J. E. Del Bene, J. Phys. Chem., 1994, 98, 5902-5905.

77 V. Barone and C. Adamo, J. Phys. Chem., 1995, 99, 1506215068.

78 P.-T. Chou, C.-Y. Wei and F.-T. Hung, J. Phys. Chem. B, 1997, 101, 9119-9126.

79 A. Dkhissi, L. Adamowicz and G. Maes, Chem. Phys. Lett., 2000, 324, 127-136.

80 A. Dkhissi, R. Ramaekers, L. Houben, L. Adamowicz and G. Maes, Chem. Phys. Lett., 2000, 331, 553-560.

81 A. Maris, P. Ottaviani and W. Caminati, Chem. Phys. Lett., 2002, 360, 155-160.
82 A. Albert and E. P. Serjeant, The determination of ionization constants : a laboratory manual, Chapman and Hall, London, 1984.

83 S. F. Mason, J. Chem. Soc., 1958, 674-685, DOI: 10.1039/ JR9580000674.

84 A. Habibi-Yangjeh, E. Pourbasheer and M. DanandehJenagharad, Monatsh. Chem., 2009, 140, 15-27.

85 Broadband dielectric spectroscopy, ed. A. S. F. Kremer, Springer, Berlin, 2003.

86 U. Kaatze, Chem. Phys. Lett., 1986, 132, 291-293.

87 T. P. Iglesias, G. Vilão and J. C. R. Reis, J. Appl. Phys., 2017, 122, 074102.

88 G. G. Hammes and P. J. Lillford, J. Am. Chem. Soc., 1970, 92, 7578-7585.

89 D. L. Pavia, G. M. Lampman, G. S. Kriz and J. A. Vyvyan, Introduction to spectroscopy, 2015.

90 S. F. Mason, 1002. The tautomerism of N-heteroaromatic hydroxy-compounds. Part II. Ultraviolet spectra, J. Chem. Soc., 1957, 0, 5010-5017.

91 G. F. Tucker and J. L. Irvin, J. Am. Chem. Soc., 1951, 73, 19231929.

92 A. Albert and J. N. Phillips, J. Chem. Soc., 1956, 1294-1304, DOI: 10.1039/JR9560001294.

93 D. Aue, B. Don, W. R. Davidson, M. T. Bowers, P. Beak and $\mathrm{J}$. Lee, Gas-phase basicities of amides and imidates. Estimation of protomeric equilibrium constants by the basicity method in the gas phase, 1979.

94 P. Beak, Acc. Chem. Res., 1977, 10, 186-192.

95 M. Kuzuya, A. Noguchi and T. Okuda, J. Chem. Soc., Chem. Commun., 1984, 435-436, DOI: 10.1039/C39840000435.

96 R. H. Cox and A. A. Bothner-By, J. Phys. Chem., 1969, 73, 2465-2468.

97 J. R. Taylor, An introduction to error analysis : the study of uncertainties in physical measurements, University Science Books, Sausalito, Calif., 1997.

98 J. Malecki, J. Mol. Struct., 1997, 436-437, 595-604.

99 H. Freedman, H. N. Nguyen and T. N. Truong, J. Phys. Chem. $B$, 2004, 108, 19043-19048. 